\title{
The Device of the Shallow Frame (Half-Frame) With Quick Fitting of a Beeswax Foundation and Its Advantage
}

\author{
Ivan Voiku \\ Department of Business management \\ and innovation management \\ Pskov State University \\ Pskov, Russia \\ voiku-ivan@yandex.ru
}

Abstract-Transformation of the world food market, caused by the change of China from the world's largest exporter into importer, and the expansion of the world food crisis, actualizes the need to solve the main problem of beekeeping - technical and technological backwardness.

Automation and mechanization of beekeeping has a long history, however the high rates of the industry are achieved mainly due to the huge costs of manual labor, time and means. The amount of time, spent by beekeepers on the service of beehives, grows in direct proportion to the expansion of the apiary, and it can be seen as an obstacle to the development of the entire industry. Fitting of a beeswax foundation in the frame is one of the most labor-intensive technological operations [1].

Description of the device of the shallow frame (halfframe), which allows to abandon the traditional technology of fitting of a beeswax foundation in favor of the new accelerated one, is presented. The device is a frame, divided longitudinally in two parts, connected together by loops. On the edges of the separated bars there are protrusions, which allow, while closing, to cut off the sheet of a beeswax foundation. The technical result of using the proposed device is simplification of the assembly process and reduction of labor costs while servicing beehive frames.

The proposed device changes the traditional technology of fitting of a beeswax foundation, reducing the number of operations of the beekeeper to: opening the frame, positioning the standard sized sheet of a beeswax foundation in the frame, cutting the sheet to the required size while closing the frame. The usage of this device will allow the beekeeper to save a significant amount of time for performing other technological operations.

Keywords - beeswax foundation, fitting of beeswax foundation, half-frames, loops, shallow frame, technology.

\section{INTRODUCTION}

Beekeeping is one of the most important branches of agricultural industry in the world. It delivers honey, flower pollen, beeswax, bee bread, propolis, apitoxin, royal jelly and other products. In addition, beekeeping plays a huge role in crop pollination.

In per capita production of honey, Russia is 1.5 times ahead of China, the US and Germany - more than 2 times, India - 8 times, and Japan - 18 times. In per capita consumption of honey, Russia also occupies a rightful place in the world ranking.

World indicators of honey production and consumption are presented in Table I.

TABLE I.

WORLD INDICATORS OF HONEY PRODUCTION AND CONSUMPTION [2].

\begin{tabular}{|l|l|l|l|l|l|l|}
\hline Country & $\begin{array}{l}\text { Production } \\
\text { of honey, } \\
\text { thousand tons }\end{array}$ & $\begin{array}{l}\text { Import } \\
\text { of honey, } \\
\text { thousand tons }\end{array}$ & $\begin{array}{l}\text { Export } \\
\text { of honey, } \\
\text { thousand tons }\end{array}$ & $\begin{array}{l}\text { Consumption } \\
\text { of honey, } \\
\text { thousand tons }\end{array}$ & $\begin{array}{l}\text { Per capita consumption, } \\
\text { grams }\end{array}$ & $\begin{array}{l}\text { Per capita } \\
\text { production, grams }\end{array}$ \\
\hline Russia & 68,4 & 1,2 & 0,5 & 69,1 & 481 & 476 \\
\hline China & 450 & 15 & 125 & 325 & 238 & 329 \\
\hline Turkey & 90 & 1 & 3 & 88 & 1147 & 1173 \\
\hline India & 80 & & 25 & 55 & 45 & 65 \\
\hline Mexico & 60 & & 33 & 27 & 219 & 498 \\
\hline Argentina & 75 & & 64,4 & 13,6 & 319 & 1760 \\
\hline Brazil & 38 & & 18,6 & 19,4 & 92 & 189 \\
\hline USA & 65 & 135 & 3,5 & 201,5 & 634 & 206 \\
\hline EU 27 & 217,7 & 147,3 & 11,8 & 352,8 & 703 & 433 \\
\hline Germany & 18 & 85 & 21 & 82 & 1016 & 223 \\
\hline Japan & 3,3 & 40 & & 43,3 & 340 & 26 \\
\hline
\end{tabular}


According to the approximate calculations of the employees of the FSBSI "Scientific and Research Institute of beekeeping," the volume of a melliferous base allows Russia to increase honey production up to 300 thousand tons and more [2].

About 7496 thousand bee colonies are required for full pollination of the entomophilic crops, available in the Russian Federation. The fodder resources of entomophilic cultivated plants of Russia are capable to provide the maintenance of 9023 thousand bee colonies. The determined melliferous resources allow to increase the number of bee colonies and the volume of marketable honey production in Russia by 8-9 times, compared to current corresponding indicators [3].

According to the forecast of the Russian National Union of beekeepers, the volume of gross honey yield may increase up to 180 thousand tons by the end of 2019 [4]. Such an optimistic scenario for the development of the industry is supported not only by the calculations of the volume of melliferous resources, but also by Russia's accession to the World Trade Organization:

1. World honey production is growing at a fairly high rate - about $2 \%$ per year.

2. Environmental issues of one of the world's major honey exporters - China can lead to an almost complete disappearance of beekeeping in its territory.

3. The need for beeswax, which no one has yet managed to synthesize chemically and which is used in more than 50 branches, is still growing.

4. Scales of the usage of biologically active honey products (honey, beeswax, propolis, pollen, royal jelly and apitoxin) in medicine, cosmetics, dietetic nutrition are rapidly growing.

5. Beekeeping is the least capital-intensive production in comparison with any other branch of animal husbandry, so it is a very suitable object for organization of a large business, and for activities that provide an additional revenue sources.

Thus, the transformation of the world food market, caused by the change of China from the world's largest exporter into importer, and the expansion of the world food crisis, actualizes the need to solve the main problem of beekeeping - technical and technological backwardness.

Automation and mechanization of beekeeping has a long history, however the high rates of the industry are achieved mainly due to the huge costs of manual labor, time and means. The amount of time, spent by beekeepers on the service of beehives, grows in direct proportion to the expansion of the apiary, and it can be seen as an obstacle to the development of the entire industry.

\section{Materials AND MEthods}

Fitting of a beeswax foundation in the frames is one of the most labor-intensive technological operations. A beekeeper must have a special tool for this operation: a template board, a special knife, a spur roller or an electrical apparatus for embedding a beeswax foundation, which replace all these tools, but require a source of electricity.

The use of a plastic beeswax foundation significantly facilitates the work of a beekeeper on fitting of a beeswax foundation in frames. Despite the absolute functional readiness of the plastic beeswax foundation, this alternative solution has a number of disadvantages, including the need to cover the plastic beeswax foundation with a layer of beeswax.

Mel'nik V. I., Romanchenko N.. and Romanchenko, V. N., the inventors of RU 2065266 dated August, 20, 1996, are trying to solve the problem of significant labor costs [5]. A beehive frame, proposed by them, contains two mirror-like half-frames, joined by a lintel with a hinge, located along two similar bars. The lintel allows for a movement of the first half-frame against the second half-frame with one degree of freedom. A sheet of a beeswax foundation, inserted between the half-frames, glues to the device by beeswax while compressing this half-frames with a certain force.

The disadvantage of this device is that the use of a beehive half-frame requires preliminary preparation of a beeswax foundation - cutting off under the size. In addition, the use of the device in a beehive together with frames of traditional size is difficult due to a difference in contours (forms). The presence of the lintel makes it possible for bees to patch up by beeswax a junction of the half-frames. The need to ensure the elastic deformation of the device limits the use of hard food grade plastic, which gives rigidity to the frame, in its production.

\section{Results AND DISCUSSION}

The staff members of the FSBEI of Higher Education "Pskov State University" have developed a

device, that can change the technology of fitting of a beeswax foundation. When using this device, a beekeeper has no need in such operations as cutting with a knife the sheet of a beeswax foundation to the required size, bending the edges of the beeswax foundation under a spur roller, installation of the beeswax foundation with a curved edge to the frame, ironing with the pre-heated roller with a few movements along the edge and along the wire. Also, there is no need to purchase and use electrical appliances for fitting of a beeswax foundation and kindling of beeswax.

The technical problem, solved by the proposed device, is not only a refusal of the necessity of cutting the sheet of a beeswax foundation into the frame size, but also ensuring the possibility of using this device in conjunction with traditional beekeeping frames, ensuring a mobility of the parts of the device without a lintel, giving rigidity to the frame and reliability of its binding with a beeswax foundation.

The proposed device is made of hard food grade plastic (for example, polyvinyl chloride), has loops and has sizes similar to the parameters of traditional 
beehive frames. One of the half-frames is provided with a protrusion along the closed edge, which allows cutting the sheet of a beeswax foundation into the frame size, and a longitudinal locking mechanism that securely holds the frame from opening [6].

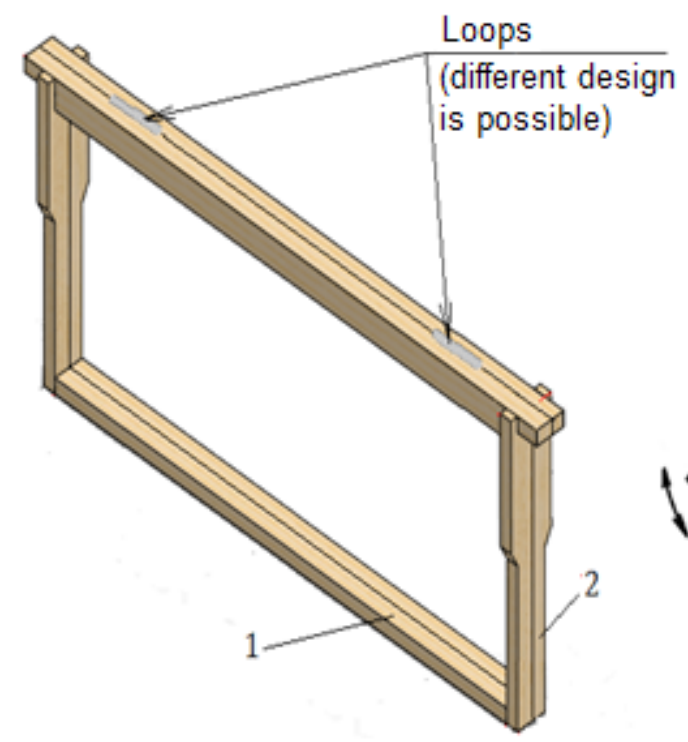

Fig. 1. Appearance and structure of the shallow frame (half-frame) with quick fitting of a beeswax foundation

The proposed device consists of two mirror-like half-frames, marked on the Fig. 1 as 1 and 2. Each of half-frames 1 and 2 has a rectangular design, conjugated together by outside loops 3 , which are positioned over the two top bars of half-frames 1 and 2. The loops allow for the movement of half-frame 1 against half-frame 2 with one degree of freedom. Half-frame 2 has a cutting protrusion 4. There is protrusion 5 on half-frame 1 , and there is recess 6 on half-frame 2, together they are forming a locking mechanism. Overall dimensions of the frame are taken according to existing standards for such structures.

The principle of operation of the proposed device is: half-frames 1 and 2 open to the required clearance between bottom bars, while top bars are held by loops 3. Sheet of a beeswax foundation 7 is positioned on halfframe 1 and is cutting to the required size by pressing halfframe 2. Half-frames glue together with beeswax from the deformed part of the sheet of a beeswax foundation, which is on a rough surface of interlocked half-frames 1 and 2.
Appearance and structure of the shallow frame (halfframe) with quick fitting of a beeswax foundation are presented on Fig. 1. 